University of Nebraska - Lincoln

DigitalCommons@University of Nebraska - Lincoln

Marjorie A. Langell Publications

Published Research - Department of Chemistry

7-1-2001

\title{
Nature of oxygen at rocksalt and spinel oxide surfaces
}

\author{
Marjorie Langell \\ University of Nebraska - Lincoln, mlangell1@unl.edu \\ J.G. Kim \\ University of Nebraska - Lincoln \\ D. L. Pugmire \\ University of Nebraska-Lincoln, pugmire@ornl.gov \\ W. McCarroll \\ Rider University, Lawrenceville, New Jersey
}

Follow this and additional works at: https://digitalcommons.unl.edu/chemistrylangell

Part of the Chemistry Commons

Langell, Marjorie; Kim, J.G.; Pugmire, D. L.; and McCarroll, W., "Nature of oxygen at rocksalt and spinel oxide surfaces" (2001). Marjorie A. Langell Publications. 3.

https://digitalcommons.unl.edu/chemistrylangell/3

This Article is brought to you for free and open access by the Published Research - Department of Chemistry at DigitalCommons@University of Nebraska - Lincoln. It has been accepted for inclusion in Marjorie A. Langell Publications by an authorized administrator of DigitalCommons@University of Nebraska - Lincoln. 


\title{
Nature of oxygen at rocksalt and spinel oxide surfaces
}

\author{
M. A. Langell, ${ }^{\text {a) }}$ J. G. Kim, and D. L. Pugmire ${ }^{\text {b) }}$ \\ Department of Chemistry, University of Nebraska, Lincoln, Nebraska 68588-0304 \\ W. McCarroll \\ Department of Chemistry, Rider University, Lawrenceville, New Jersey 08648-3099
}

(Received 12 September 2000; accepted 18 December 2000)

\begin{abstract}
The chemical environment of oxygen in cobalt-containing metal oxides with compositions $\mathrm{M}_{x} \mathrm{M}_{(x-1)}^{\prime} \mathrm{O}$ and $\mathrm{M}_{x} \mathrm{M}_{(3 x-1)}^{\prime} \mathrm{O}_{4}\left(\mathrm{M}, \mathrm{M}^{\prime}=\mathrm{Mn}, \mathrm{Ni}, \mathrm{Co}\right)$ has been studied by Auger, $\mathrm{x}$-ray and ultraviolet photoelectron, and high resolution electron energy loss spectroscopies. While there is a single type of lattice oxygen in the bulk structure of simple rocksalt and spinel oxides, the nature of oxygen at the surface of the spinel oxides is considerably more complex. Photoemission from core oxygen states in these materials often shows multiple peaks and satellite structure which have been attributed to a range of intrinsic and extrinsic oxygen states. All of these $3 d$ transition metal oxides show a single, intense O $1 s$ core photoemission peak at approximately $529.6 \mathrm{eV}$. In the spinel materials, a second state at $531.2 \mathrm{eV}$ is also observed and is shown to be intrinsic to the spinel surface and not a result of hydroxylation or other surface contaminant. Similar photoemission features in $\mathrm{Fe}_{3} \mathrm{O}_{4}$ were previously attributed to final state effects; however, the nature of the multiple final states remains to be elucidated. (C) 2001 American Vacuum Society.
\end{abstract}

[DOI: $10.1116 / 1.1349194]$

\section{INTRODUCTION}

Transition metal oxides (TMOs) form an important class of materials and find use in heterogeneous catalysis, as electronic and magnetic devices, as gas sensors, and in a host of other solid-state applications. A subset of this class, the cubic transition metal oxides, can be envisioned as a close-packed array of $\mathrm{O}^{2-}$ lattice anions with cations filling various fractions of octahedral and tetrahedral interstitial sites. Rocksalt oxides, e.g., $\mathrm{NiO}$ and $\mathrm{Ni}_{x} \mathrm{Co}_{1-x} \mathrm{O}$, fill all octahedral sites with cations formally in the $2+$ oxidation state. Spinels, e.g., $\mathrm{Co}_{3} \mathrm{O}_{4}$, populate half their octahedral sites with $3+$ cations while one-eighth of their tetrahedral sites are filled with $2+$ cations. Inverse spinels, e.g., $\mathrm{Fe}_{3} \mathrm{O}_{4}$ and $\mathrm{NiCo}_{2} \mathrm{O}_{4}$, form a related structure; the $2+$ cations now occupy octahedral sites with the $3+$ cations divided equally between the remaining filled octahedral sites and tetrahedral sites of the lattice. Because of the similarity in lattice structure, spinels and rocksalt oxides often interconvert at TMO surfaces,${ }^{1-4}$ depending upon the oxidizing/reducing nature of their environment. Substitutional and interstitial defects are also common in these materials ${ }^{5}$ and surface compositions can differ from that of the bulk due to either thermodynamic or kinetic factors. ${ }^{4,6}$

Water is one oxidant commonly encountered under ambient conditions, and most air-exposed TMOs are covered with one or more hydroxylated layers. ${ }^{7}$ While hydroxylation occurs rapidly under ultrahigh vacuum (UHV) only at isolated defect sites, ${ }^{8,9}$ air-exposed TMO substrates can form relatively thick hydroxylated layers that persist in UHV to tem-

\footnotetext{
a) Author to whom correspondence should be addressed; electronic mail: mlangell@unlserve.unl.edu

${ }^{\text {b) Present address: National Institute of Standards and Technology, } 100 \mathrm{Bu}-}$ reau Dr. Stop 8362, Gaithersburg, MD 20899-8362.
}

peratures of $973 \mathrm{~K}$ or higher for substantial periods of time. As a result, it is not surprising to find a significant fraction of surface oxide as hydroxyl on air-exposed materials using standard UHV-based surface analytical techniques One example of this is in $\mathrm{O} 1 \mathrm{~s}$ photoemission spectrum, ${ }^{10}$ where TMO lattice oxide gives a characteristic feature at a binding energy of approximately $529.6 \mathrm{eV}$ and hydroxyls are found $1-2 \mathrm{eV}$ higher. Because of their ubiquitous nature, the converse is also assumed and any feature found within $1-2 \mathrm{eV}$ higher binding energy in the $\mathrm{O} 1 s$ photoemission spectrum is automatically taken as proof of surface hydroxylation.

We show here that cobalt-containing spinel TMO surfaces often show photoemission with two distinct peaks in the $\mathrm{O}$ $1 s$ spectrum. The more intense feature, at $529.5 \pm 0.2 \mathrm{eV}$, is comparable to the main lattice oxygen peak found on rocksalt substrates and commonly reported for lattice oxide on spinels and other TMO substrates. The second, found with $\sim 40 \%$ the intensity of the main substrate peak, has a binding energy of $531.2 \pm 0.2 \mathrm{eV}$ and is often confused with hydroxyl contamination. However, this feature is found on $\mathrm{Ar}^{+}$-sputtered and extensively UHV-annealed substrates, at thin spinel films grown on metal or on metal oxides under UHV and on vacuum-cleaved single crystals, conditions that should not produce substantial water or hydroxyl contamination. Furthermore, other surface analytical techniques indicate that these surfaces are both hydroxyl and carbonate free. Thus, both of these peaks must be intrinsic to the spinel surface or to a high-concentration, easily formed oxide defect state associated with the creation of tetrahedral sites on TMO oxide surfaces.

Determining the exact nature of the species or mechanism giving rise to the higher binding energy $\mathrm{O} 1 s$ peak in cobaltcontaining spinels requires further study. However, it is clear that in the absence of supporting information $\mathrm{x}$-ray photo- 
electron spectroscopy does not unequivocally establish the presence of TMO surface hydroxylation merely through the presence of a second, higher binding energy peak in the $\mathrm{O} 1 \mathrm{~s}$ spectrum. Photoemission studies on well-defined $\mathrm{Fe}_{3} \mathrm{O}_{4}(001)$ substrates ${ }^{11}$ find a feature at comparable binding energies to the $531.2 \mathrm{eV}$ peak of the present studies. The peak is lower in binding energy than $\mathrm{O} 1 s$ photoemission from deliberately hydroxylated iron oxide surfaces ${ }^{8,11,12}$ and is intrinsic to the spinel surface. This feature has been suggested to result from final state effects in the photoemission process.

\section{EXPERIMENTAL DETAILS}

All experimentation was carried out in a 401 UHV chamber operating at a base pressure of approximately $3 \times 10^{-8}$ Pa maintained by a combination of turbo and ion pumping. The bell jar was equipped with a double pass cylindrical mirror analyzer for Auger electron spectroscopy (AES) and $\mathrm{x}$-ray photoelectron (XPS) spectroscopies, a four-grid set of low energy electron diffraction (LEED) optics, a single pass $127^{\circ}$ sector high resolution electron energy loss spectrometer (HREELS) and provisions for gas dosing, heating, and argon ion bombardment.

Powdered samples were introduced to UHV via a load lock system and were subjected to a brief sputtering $\left(\mathrm{Ar}^{+}, 5\right.$ $\min$, at $0.5 \mathrm{kV}$ and $1.5 \mu \mathrm{A} / \mathrm{cm}^{2}$ ) prior to analysis. $\mathrm{NiCo}_{2} \mathrm{O}_{4}{ }^{13,14}$ powders were prepared by sol-gel methods and $\mathrm{MnCo}_{2} \mathrm{O}_{4}$ were prepared by thermal decomposition from nitrates. ${ }^{15,16}$ The homogeneity and bulk stoichiometry of the two samples were determined with powder x-ray diffraction using a Rigaku Geigerflex diffractometer equipped with a $\mathrm{Cu}$ $K \alpha$ anode.

Single crystal substrates were cleaved under UHV. The $\mathrm{CoO}$ single crystal, obtained form Atomergic Chemetal Corp, was cleaved to reveal a (100) surface orientation as confirmed by LEED. The $\mathrm{Co}_{3} \mathrm{O}_{4}$ surface was obtained in two ways: the first, by UHV cleavage of bulk $\mathrm{Co}_{3} \mathrm{O}_{4}$ single crystals grown electrolytically from carbonate melts, which left a cracked but otherwise clean and previously unexposed surface; the second, by slow oxidation of $\mathrm{CoO}(100)$ single crystal substrates, which give XPS, AES, LEED, and HREELS phonon spectra in agreement with $\mathrm{Co}_{3} \mathrm{O}_{4}(100)$ formation. ${ }^{1,2}$

AES and XPS surface analysis was performed with a Physical Electronics 15-255G double-pass cylindrical mirror analyzer. AES was taken in a lock-in derivative mode with a $2 \mathrm{keV}$ primary beam energy, a scan rate of $1.0 \mathrm{eV} / \mathrm{s}$, a modulation energy of $2 \mathrm{eV}$ and a time constant of $0.1 \mathrm{~s}$. The AES spectra were signal averaged for ten scans. XPS was obtained in a pulse-count mode at a constant pass energy of 25 $\mathrm{eV}$. Photoemission was initiated with $\mathrm{Mg} K \alpha$ radiation ( $h \nu$ $=1253.6 \mathrm{eV}$ ) and the photoelectrons were detected in an angular aperture at $44^{\circ}$ relative to the surface normal. The spectra, taken in increments of $0.1 \mathrm{eV}$ with dwell times of 50 $\mathrm{ms}$, were signal averaged for at least 100 scans. First measurements of XPS binding energies were calibration through an $\mathrm{Au} 4 f_{7 / 2}$ peak at $83.8 \mathrm{eV}$, either from gold evaporated onto single crystal surfaces or from a gold foil used for mounting powder samples. However, the lattice O $1 s$ peak

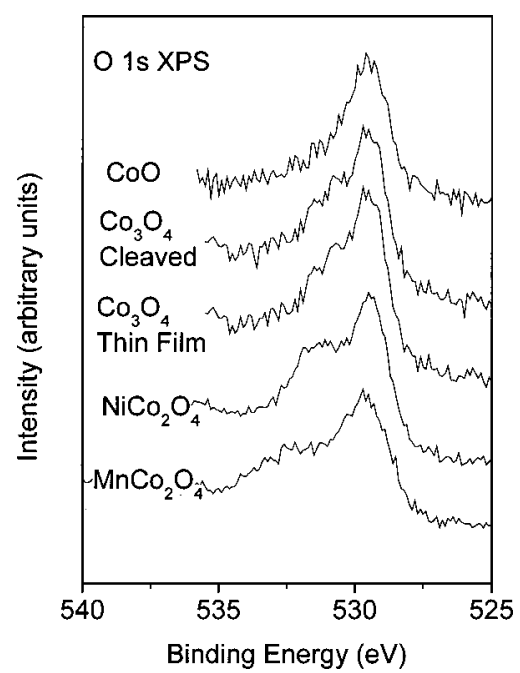

FIG. 1. O $1 s$ X-ray photoelectron spectra taken at $25 \mathrm{eV}$ pass energy for several cobalt-containing TMO materials.

was found to be constant at $529.6 \pm 0.2 \mathrm{eV}$ and this value was more conveniently used as an internal standard in subsequent measurements. HREELS data were obtained with a home-built, single-pass $127^{\circ}$ sector at $3.7 \mathrm{eV}$ primary beam energy and with an ultimate resolution of approximately 7 meV.

Ultraviolet photoelectron spectroscopy (UPS) was performed at the National Synchrotron Light Source in Brookhaven National Laboratory ${ }^{7}$ with an incident beam angle of $56^{\circ}$ relative to the surface normal and in normal emission detection. A Vacuum Generators APES 400 hemispherical analyzer was run at $12 \mathrm{eV}$ pass energy and the overall resolution of the spectrometer/beam line was approximately $178 \mathrm{meV}$ at $30 \mathrm{eV}$ primary beam energy. No decomposition or other changes were observed during the course of this or any other data acquisition.

\section{RESULTS}

Oxygen $1 s$ XP spectra are presented for a number of cobalt-containing oxides in Fig. 1. Assuming exponential attenuation and a mean free path of $11 \AA,^{10}$ it can be estimated that $95 \%$ of the XPS signal results from approximately the outermost $25 \AA$ of the surface using the present photoelectron detection geometry and excitation source. $\mathrm{CoO}$ rocksalt substrates show a single $\mathrm{O} 1 \mathrm{~s}$ peak to within the resolution of the spectrum and the five-coordinated $\mathrm{O}^{2-}$ of the outermost surface layer are not resolved from the six-coordinated lattice oxide of subsequent near-surface layers. The single $\mathrm{O}$ $1 s$ peak obtained for the cleaved-crystal $\mathrm{Co}(100)$ surface has a maximum binding energy of $529.6 \mathrm{eV}$ and tails gently to the higher binding energy side due to inelastic scattering of the photoelectrons. The spectrum is similar to $\mathrm{CoO} \mathrm{O} 1 \mathrm{~s}$ photoemission data reported elsewhere., ${ }^{2,10,17-20}$

Unlike the rocksalt oxide, the cobalt-containing spinel materials, $\mathrm{Co}_{3} \mathrm{O}_{4}, \mathrm{NiCo}_{2} \mathrm{O}_{4}$, and $\mathrm{MnCo}_{2} \mathrm{O}_{4}$, all show evidence for more complicated structure to the high-binding energy side of the main $\mathrm{O} 1 s$ lattice peak. The main lattice 


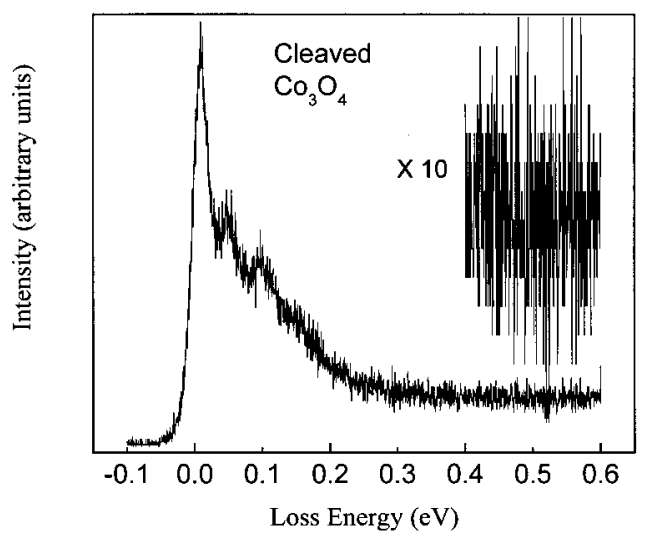

FIG. 2. HREEL spectrum of UHV-cleaved $\mathrm{Co}_{3} \mathrm{O}_{4}$ taken at $3.7 \mathrm{eV}$ primary beam voltage and $10 \mathrm{meV}$ resolution. The loss features result in multiple scattering from lattice Fuchs-Kliewer phonons and do not show any contribution from high loss $(\sim 400 \mathrm{meV})$ hydroxyl stretches.

peak is within error of that found for $\mathrm{CoO}$ for all samples, but an additional peak is now apparent at approximately $531.2 \mathrm{eV}$. This higher binding energy feature occurs with substantial intensity, even for UHV-grown $\mathrm{Co}_{3} \mathrm{O}_{4}$ films and for UHV-cleaved $\mathrm{Co}_{3} \mathrm{O}_{4}$ single crystals which are unlikely to have substantial amounts of contamination or defect concentration. Efforts to detect hydroxyls or other known defects and contaminants by additional surface-sensitive techniques showed their concentrations to be below the limits of the measurement. For example, HREELS data taken on UHVcleaved $\mathrm{Co}_{3} \mathrm{O}_{4}$ are shown in Fig. 2 and while a welldeveloped Fuchs-Kliewer phonon spectrum is clearly evident, the characteristic hydroxyl stretching region $(\sim 0.40$ $\mathrm{eV})$ remains featureless. $\mathrm{NiO}(111)$ thin films are stabilized by an outermost hydroxylated layer under UHV conditions and, in this case, HREELS is able to detect $\leqslant 0.25$ monolayer concentrations of surface hydroxyls with no difficulty. ${ }^{21}$

Simple curve fitting of the $\mathrm{O} 1 \mathrm{~s}$ spectrum with Gaussian functions (Fig. 3) indicates this feature to be $40 \%-70 \%$ the intensity of the main lattice peak at $529.6 \mathrm{eV}$. The simplicity of the fitting most likely overestimates both the peak width (full width at half maximum $\sim 1.4 \mathrm{eV}$ ) and intensity since defects, impurities and inadequacies of the fitting procedure all are expected to shift intensity to the high binding energy side of the main lattice peak. Even within these limitations, however, it is clear that the feature represents more than casual contamination expected for an in situ cleaved single crystal sample.

The powder samples $\left(\mathrm{Ni}_{2} \mathrm{Co}_{2} \mathrm{O}_{4}\right.$ and $\left.\mathrm{MnCo}_{2} \mathrm{O}_{4}\right)$ were by necessity synthesized under flowing, dry air at atmospheric pressures $^{13-16}$ and exposed briefly $(\sim 15 \mathrm{~min})$ to ambient air in transferring them to UHV. This is ample time and opportunity for substantial hydroxylation to occur and the O $1 s \mathrm{XP}$ spectrum can arguably be fit to three or more peaks (Fig. 3). However, even when the powders are annealed for extensive periods under UHV, the second higher binding energy peak is still observed with substantial intensity. Figure 4(b) shows the $\mathrm{O} 1 s$ peak shape for powdered $\mathrm{Ni}_{2} \mathrm{Co}_{2} \mathrm{O}_{4}$ after annealing for $2 \mathrm{~h}$ in $\mathrm{UHV}$ at $750 \mathrm{~K}$, a temperature comparable to that

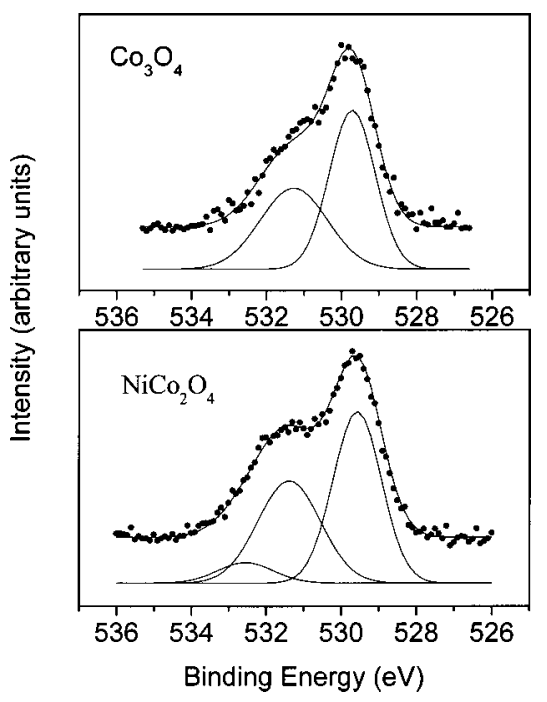

FIG. 3. Peak fit routine for $\mathrm{O} 1 \mathrm{~s}$ photoemission from $\mathrm{Co}_{3} \mathrm{O}_{4}$ cleaved-crystal and $\mathrm{NiCo}_{2} \mathrm{O}_{4}$ powder samples. In both cases, a linear background was removed and the peak was fit to a minimum number of Gaussian peaks so that $R$ values of $>0.98$ were obtained.

reported for surface (625 K, Ref. 13) and bulk (723 K, Ref. 14) decomposition into the constituent monoxides. While the intensity of the $531.2 \mathrm{eV}$ peak does decrease noticeably upon annealing, it can be almost completely restored to its initial intensity by annealing under low pressures of oxygen gas in the UHV chamber. Figure 4(c) shows the results of annealing under $1.3 \times 10^{-4} \mathrm{~Pa}$ at $625 \mathrm{~K}$ for $2 \mathrm{~h}$.

While cleaved-surface single crystal measurements should prove most ideal for unequivocally preparing welldefined and contaminant free surfaces, $\mathrm{Co}_{3} \mathrm{O}_{4}$ does not have as stable a cleavage plane as does the rocksalt $\mathrm{CoO}$. This coupled, with the small size of the crystals $(\sim 0.2-0.5 \mathrm{~cm})$, could have resulted in a higher than typical fraction of defect

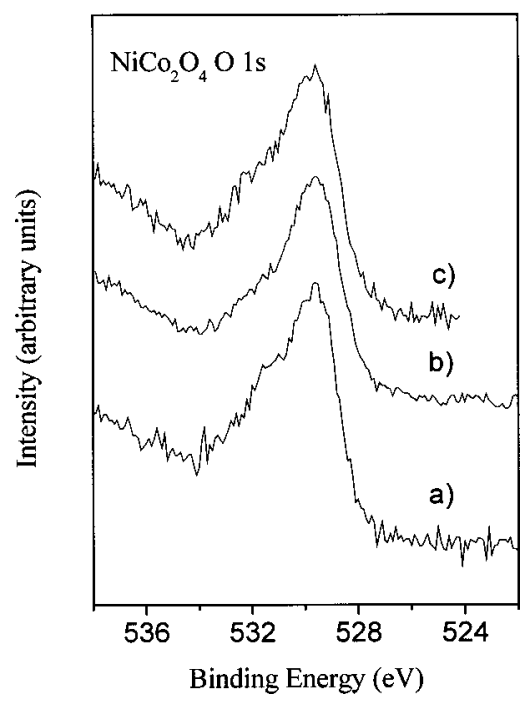

FIG. 4. O $1 \mathrm{~s}$ spectrum for $\mathrm{NiCo}_{2} \mathrm{O}_{4}$ powders (a) stoichiometric, (b) the stoichiometric sample of trace a reduced by heating under UHV to $750 \mathrm{~K}$ for $2 \mathrm{~h}$, and (c) the reduced sample of trace b heated under $1.3 \times 10^{-4} \mathrm{~Pa} \mathrm{O}_{2}$ for $2 \mathrm{~h}$. 


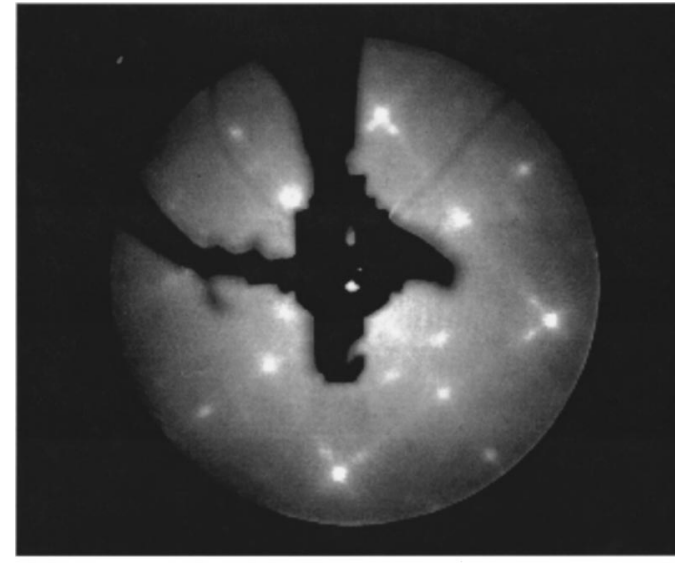

$85 \mathrm{eV}$ beam voltage

FIG. 5. LEED pattern of a $\mathrm{Co}_{3} \mathrm{O}_{4}$ thin-film grown epitaxially upon single crystal $\mathrm{CoO}(100)$.

sites generated in UHV cleavage of the $\mathrm{Co}_{3} \mathrm{O}_{4}$ single crystal substrates. Indeed, the cleaved surface did not present a smooth, unblemished crystalline face even on the macroscopic scale but showed several large cracks and steps. For this reason, data on thin-film $\mathrm{Co}_{3} \mathrm{O}_{4}$ are also included in the present study. Because the films are grown by slow oxidation of $\mathrm{CoO}(100)$ under high vacuum conditions, ${ }^{1,2}$ these films are restricted to the $\mathrm{Co}_{3} \mathrm{O}_{4}(100)$ orientation of the epitaxy. They are, however, very well ordered (Fig. 5) and give characteristic cobalt $2 p$ spinel peak shapes (Fig. 6). Additionally, both XPS O $1 s / \mathrm{Co} 2 p$ and AES O KLL/Co LMM intensity ratios indicate that full oxidation from $\mathrm{CoO}$ to $\mathrm{Co}_{3} \mathrm{O}_{4}$ has occurred to within the depth of the XPS and AES measurements. The $\mathrm{O} 1 s$ peak shape for this thin film is comparable to that of the cleaved $\mathrm{Co}_{3} \mathrm{O}_{4}$ single-crystal surface (Fig. 1).

As with the powdered samples, the $\mathrm{Co}_{3} \mathrm{O}_{4}$ thin films can be reversibly oxidized and reduced. UPS of the oxidation/ reduction process is shown in Fig. 7 for thin films of $\mathrm{Co}_{3} \mathrm{O}_{4}$ grown upon $\mathrm{CoO}(100)$ bulk substrates and the process can be

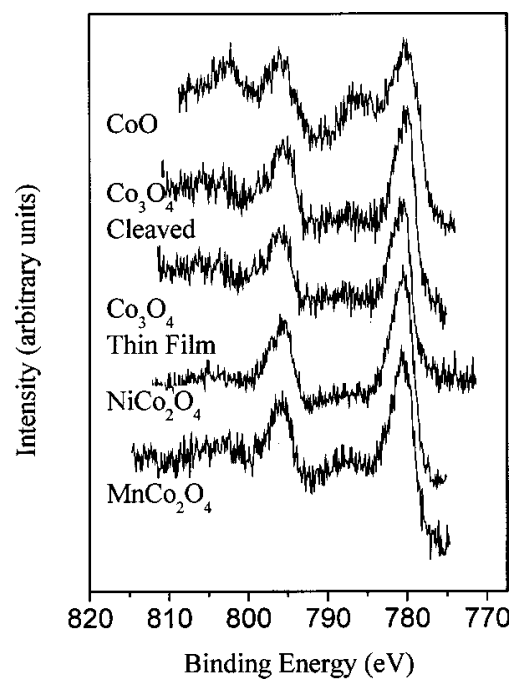

FIG. 6. Co $2 p$ x-ray photoelectron spectra taken at $25 \mathrm{eV}$ pass energy for several cobalt-containing TMO materials.

seen to be completely reversible. Heating the $\mathrm{CoO}(100)$ substrate under $1.3 \times 10^{-2} \mathrm{~Pa}$ for approximately $4 \mathrm{~h}$ at $623 \mathrm{~K}$ converts the near-surface into a material with substantially sharper, more intense electron density near the valence band maximum in the UP spectrum. Heating this thin film under $\mathrm{UHV}$ or $\mathrm{H}_{2}$ allows the $\mathrm{CoO}(100)$ substrate to reform. During the oxidation/reduction cycle the $\mathrm{O} 1 s$ peak shape goes from a single $\mathrm{O} 1 s$ peak at $529.6 \mathrm{eV}$, although tailed to higher binding energies to reflect the secondary electron structure, to the double-peaked spectrum shown in Fig. 1 and back again.

The sharp nature of the valence band observed for the $\mathrm{CoO}(100) / \mathrm{Co}_{3} \mathrm{O}_{4}$ thin film is entirely consistent with the $d^{6}$ low spin nature of octahedrally coordinated $\mathrm{Co}^{3+}$ cations of the spinel structure since the diamagnetic nature of the octahedrally coordinated $\mathrm{Co}^{3+}$ allows for a very sharp peak. The majority of the contribution of tetrahedral $\mathrm{Co}^{2+}$ cations to the valence band occurs approximately $2-3 \mathrm{eV}$ below the valence band maximum. ${ }^{1}$ Defect states would serve to
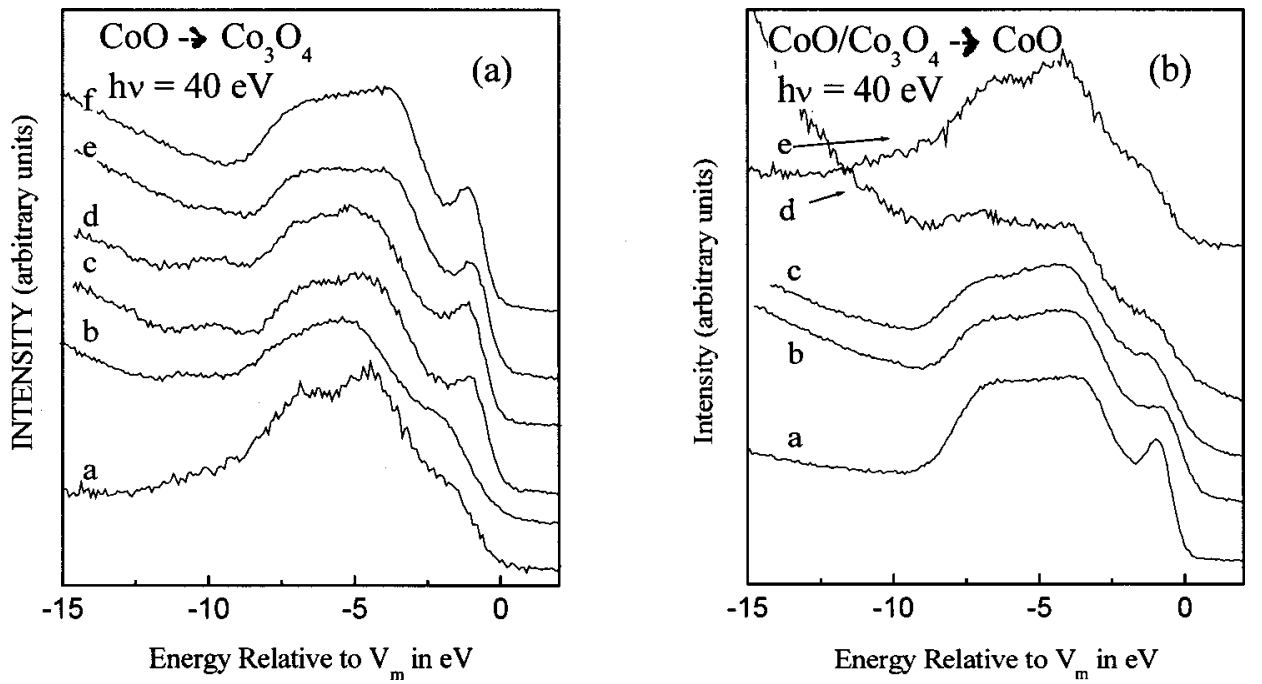

FIG. 7. Normal emission UPS taken during $\mathrm{CoO}(100) / \mathrm{Co}_{3} \mathrm{O}_{4}$ epitaxial oxidation and reduction. Panel a: oxidation of $\mathrm{CoO}(100)$ under $1.3 \times 10^{-2} \mathrm{~Pa}$ $\mathrm{O}_{2}$ at $623 \mathrm{~K}$ for (a) $0 \mathrm{~h}(\mathrm{CoO})$, (b) 0.5 h, (c) $1.0 \mathrm{~h}$, (d) $2.0 \mathrm{~h}$, (e) $3.0 \mathrm{~h}$, and (f) $4.0 \mathrm{~h}$ total oxidation. Panel b: reduction of $\mathrm{CoO}(100) / \mathrm{Co}_{3} \mathrm{O}_{4}$ epitaxy by heating under UHV at 1073 for (a) $0 \mathrm{~h}$ $\left(\mathrm{Co}_{3} \mathrm{O}_{4}\right)$, (b) $0.25 \mathrm{~h}$, (c) $0.5 \mathrm{~h}$, (d) $1 \mathrm{~h}$, and (e) $2 \mathrm{~h}$ 
broaden the top of the valence band and introduce defects into the band gap, neither of which occurs to any detectible extent. Also of importance is the lack of valence band features commonly associated with hydroxyls, ${ }^{11,12}$ an observation supported by extensive HREELS analysis. ${ }^{2}$

\section{DISCUSSION}

Cobalt-containing spinels give an $\mathrm{O} 1 s$ spectrum with a main lattice peak at $529.6 \mathrm{eV}$, in good agreement with other TMO $\mathrm{O}^{2-}$ close-packed oxides. The spinels also exhibit a feature at approximately $531.2 \mathrm{eV}$ as a distinct shoulder to the main peak with $40 \%-70 \%$ the main peak intensity. This higher binding energy satellite peak is observed on a number of different mixed-metal oxide spinels and is found on powders, thin-film epitaxies and in situ cleaved single crystal samples. Due to its relatively intense nature, it is unlikely to result from a defect or surface contaminant species, particularly since many of the substrates upon which it is found show very well ordered and clean surfaces.

Previous studies on the inverse spinel $\mathrm{Fe}_{3} \mathrm{O}_{4}(001)^{11}$ have reported a similar state found as a less distinct but nevertheless comparatively intense shoulder on the main lattice $\mathrm{O} 1 \mathrm{~s}$ photoemission spectrum. Photoemission studies of other $\mathrm{Fe}_{3} \mathrm{O}_{4}$ orientations report a single, but very broad, $\mathrm{O} 1 s$ peak for the stoichiometric surfaces. ${ }^{12}$ Few core-level photoemission studies have been reported on single crystal cobaltcontaining spinels, or on other spinel materials, but a host of publications can be found on powders or oxidized foils. ${ }^{10,22}$ Almost all powder studies either report a single feature in the $\mathrm{O} 1 \mathrm{~s}$ photoelectron spectrum or used curve-fitting procedures to separate one or more higher binding energy peaks from the main $\mathrm{O} 1 \mathrm{~s}$ line that are then attributed to surface defects, hydroxylation, and/or water adsorption.

While intrinsic to the spinel surface, the origin of the satellite structure is not clear. Previously satellite structure has been attributed to final state effects, ${ }^{11}$ however, the nature of the two final states represented in the $\mathrm{O} 1 \mathrm{~s}$ spectrum and the mechanism for producing them is not apparent. Cobalt $2 p$ photoemission (Fig. 6) from rocksalt oxides shows strong final state effects resulting from the charge-transfer (hybridized) nature of the rocksalt band structure

$$
\begin{aligned}
& \Psi_{\text {valence }}=\alpha 3 d^{7}+\beta 3 d^{8} L+\gamma 3 d^{9} L^{2}+\ldots, \\
& 2 p^{6} \Psi_{\text {valence }}+h \nu \rightarrow 2 p^{5} 3 d^{6}+e^{-} \rightarrow 2 p^{5} 3 d^{7} \underline{L}+e^{-},
\end{aligned}
$$

where $L$ represents an electron hole on a adjacent $\mathrm{O} 2 p$ and $\alpha, \beta, \bar{\gamma}$, etc. represent mixing coefficients for the ground state with the $\mathrm{Co}^{2+} 3 d^{7}$ cation in the valence band structure. This satellite feature is suppressed by the formation of low spin $\mathrm{Co}^{3+} 3 d^{6}$ and it is clear that unpaired electrons or occupied $e_{g}$ states are required to allow detectible amounts of both mechanisms.

The spinel structure has 56 atoms per unit cell and in the $\langle 100\rangle$ orientation takes six different layers to span a single unit cell. This presents a complex set of possibilities both for surface termination and for theoretical support from band structure calculations needed to elucidate any final state ef- fects that might occur. An obvious place to look for answers as to the identity of the $531.2 \mathrm{eV}$ satellite peak is in the chemical environment created around the surface lattice oxygen as a result of the tetrahedral cobalt cations, since this is the primary change from going from the rocksalt to the spinel surface structure. Creation of tetrahedral cobalt cations can easily be envisioned on rocksalt (100) substrates merely by removing the octahedral cation (five coordinate on the rocksalt surface) and placing it in a bridging site between two surface oxygens.

A final point to be made concerns the use of XPS, particularly with packaged peak-fit routines, as an analytical tool with no other supporting information. In surface studies of oxide materials where XPS plays a significant role, the formation of hydroxyls is treated as a forgone conclusion when any additional structure is observed to higher binding energy, and peak-fitting routines are used to deconstruct the O $1 s$ peak shape in line with this assumption. There is no question that hydroxylation represents a ubiquitous phenomenon for oxide surfaces and XPS plays a valuable role in the analysis of hydroxylated TMO surfaces. However, this assignment may not be unique and other assumptions can lead to significantly different but equally reasonable conclusions.

\section{CONCLUSIONS}

Cobalt-containing TMOs consistently show a main lattice oxygen peak at approximately $529.6 \mathrm{eV}$ and a satellite peak to higher binding energies $(\sim 531.2 \mathrm{eV})$. While this feature is easily mistaken for a contaminant hydroxyl surface species, we have shown that it is found on single crystals cleaved under UHV, thin films grown under low pressure of oxygen in UHV environs, powder samples briefly exposed to air and sputtered as a pretreatment to photoemission studies and a number of these surfaces that have been reduced and reoxidized under UHV. All these treatments yield a similar satellite peak. Furthermore, other analytical techniques show that the surfaces are well-ordered and contaminant-free to the detection limits of the technique. This shows the satellite structure to be intrinsic to the surface of cobalt-containing spinels. The specific nature of the satellite is not known, although final state effects have been suggested to be operant in photoemission mechanisms for similar substrates. The studies call into question, however, the practice of using XPS to identify such features with hydroxylation in the absence of supporting information.

\section{ACKNOWLEDGMENTS}

The authors gratefully acknowledge NSF for support under CHE-96166690 and the State of Nebraska under the Center for Materials Research and Analysis Research Initiative.

\footnotetext{
${ }^{1}$ M. A. Langell, G. A. Carson, M. Anderson, S. Smith, and L. Peng, Phys. Rev. B 59, 4791 (1999).

${ }^{2}$ G. Carson, M. H. Nassir, and M. A. Langell, J. Vac. Sci. Technol. A 14, 1637 (1996).

${ }^{3}$ M. A. Langell, C. W. Hutchings, G. A. Carson, and M. H. Nassir, J. Vac. Sci. Technol. A 14, 1656 (1996)
} 
${ }^{4}$ M. W. Nydegger, G. Couderc, and M. A. Langell, Appl. Surf. Sci. 147, 58 (1999)

${ }^{5}$ P. A. Cox, Transition Metal Oxides: An Introduction to Their Electronic Structure and Properties (Clarendon, New York, 1992).

${ }^{6}$ M. A. Langell, F. Gevrey, and M. W. Nydegger, Appl. Surf. Sci. 445, 114 (2000).

${ }^{7}$ P. Jackson and G. D. Parfitt, Trans. Faraday Soc. 67, 2469 (1971).

${ }^{8}$ T. Kendelewicz, P. Liu, C. S. Doyle, G. E. Brown, Jr., E. J. Nelson, and S. A. Chambers, Surf. Sci. 453, 32 (2000).

${ }^{9}$ J. L. Mackay and V. E. Henrich, Phys. Rev. B 39, 6156 (1989).

${ }^{10}$ D. Briggs and M. P. Seah, Practical Surface Analysis (Wiley, New York, 1990).

${ }^{11}$ S. A. Chambers and S. A. Joyce, Surf. Sci. 420, 111 (1999).

${ }^{12}$ Y. Joseph, W. Ranke, and W. Weiss, J. Phys. Chem. B 104, 3224 (2000).

${ }^{13}$ J.-G. Kim, D. L. Pugmire, D. Battaglia, and M. A. Langell, Appl. Surf. Sci. 165, 70 (2000).
${ }^{14}$ M. El Baydi, S. K. Tiwari, R. N. Singh, J. L. Rehspringer, P. Chantier, J. F. Koenig, and G. Poillerat, J. Solid State Chem. 116, 157 (1995).

${ }^{15}$ E. Rios, J.-L. Gautier, G. Pillerat, and P. Chartier, Electrochim. Acta 44, 1491 (2998).

${ }^{16}$ J. M. Jimenez Mateoa, J. Morales, and J. L. Tirado, J. Solid State Chem. 82, 87 (1989).

${ }^{17}$ V. M. Jimenez, A. Fernandez, J. P. Espinos, and A. R. Gonzales-Elipe, J. Electron Spectrosc. Relat. Phenom. 71, 61 (1995).

${ }^{18}$ B. Marcus-Saubat, J. P. Beaufils, and Y. Barbaux, J. Chem. Phys. 83, 317 (1986).

${ }^{19}$ C. R. Brundle, T. J. Chuang, and D. W. Rice, Surf. Sci. 60, 286 (1976).

${ }^{20}$ Z.-X. Shen et al., Phys. Rev. B 42, 1817 (1990).

${ }^{21}$ M. A. Langell and M. H. Nassir, J. Phys. Chem. 99, 4162 (1995).

${ }^{22}$ K. Wandelt, Surf. Sci. Rep. 2, 1 (1982). 